Thorax (1970), 25, 669.

\title{
Growth of the alveoli and pulmonary arteries in childhood
}

\author{
G. DAVIES and LYNNE REID \\ Department of Experimental Pathology, Institute of Diseases of the Chest, \\ Brompton Hospital, London, S.W.3
}

Since alveolar and airway growth have previously been studied in greater detail than has arterial growth, the present study establishes the growth pattern of the arteries and relates this to that of the alveoli and airways.

The pattern of post-natal alveolar multiplication found is similar to that reported by Dunnill, but for all ages about $10 \%$ above his figure. Alveolar size hardly changes in the first three or four years of life but thereafter increases steadily. The complexity of alveolar shape increases from the age of 4 months.

In arteriograms the arterial lumen, both centrally and peripherally, increases 4- to 5-fold in the upper lobe, 3-fold in the lower. Microscopic examination shows a striking increase between 4 months and 3 years in the number of arteries below $200 \mu \mathrm{m}$. per unit area of lung tissue ; after 5 years this number falls slightly, probably reflecting an increase in alveolar size.

Muscular, partially muscular and non-muscular arteries show a similar distribution over the same size range in the newborn as in the adult. During childhood, however, the arteries over this size range are free of muscle and much larger arteries show this mixed 'population'. Between 11 and 19 years the adult pattern forms by progressive penetration of muscle into the acinus.

The thickness of the muscle coat of pulmonary artery branches falls to adult levels by the age of 4 months. Between birth and 5 years the medial area of arteries between 25 and $200 \mu \mathrm{m}$. in diameter per unit area of lung falls, but has risen again by 11 years.

Airways, alveoli and blood vessels each have a distinctive pattern of growth, varying widely from each other in the ante-natal and post-natal periods. This has recently been expressed in the following three Laws of Lung Development (Reid, 1967a): 1. The bronchial tree is developed by the 16 th week of intra-uterine life.

2. Alveoli, as commonly understood, develop after birth, increasing in number until the age of 8 years and in size until growth of the chest wall is finished.

3. Blood vessels are remodelled and increase, certainly while new alveoli are forming and probably until the growth of the chest is complete.

\section{AIRWAYS}

Bucher and Reid (1961) have shown that by the 16th week of intra-uterine life all the bronchial generations are present. Indeed the number slightly exceeds the number found in the adult. Boyden $(1965 ;$ 1967) has demonstrated that alveoli form in the walls of some non-respiratory bronchioli at least up to the age of 3 years, leading to a fall in the number of non-respiratory generations. This affects only the most distal one or two generations of bronchioli along any pathway (Boyden, personal communication).

\section{ALVEOLI}

Multiplication of the alveoli after birth has been described by Dunnill (1962a, b), using the quantitative methods of Weibel and Gomez (1962). He found that the number of alveoli in both lungs rises from about $20 \times 10^{6}$ at birth to about $300 \times 10^{6}$ by the age of 8 years, and thereafter remains constant. In the child lung he also measured the increase in surface area with age. Boyden (1965) has pointed out that the air spaces in the lungs of a newborn child have neither the shape nor the dimensions of true alveoli, and he prefers to call the air spaces in the newborn 'saccules'; alveoli of the adult type develop after birth. 


\section{PULMONARY ARTERIES}

Reid's third Law has been less well quantified. It is clear that the pulmonary arteries must increase during the period of alveolar multiplication, but the details of rate of growth in size and number and of alterations in structure are not clearly described.

Rosen, Bowden, and Uchida (1957), studying microscopic sections of lungs in which the pulmonary arterial tree had not been injected, measured the area of the medial coat of those pulmonary arteries cut in cross-section. They related the arteries to their accompanying respiratory airways to indicate their level in the lung, as had been suggested by O'Neal, Thomas, and Hartroft (1955). Dividing their cases into children under and over 1 month of age, they reported that the medial coat 'becomes thinned' soon after birth.

Wagenvoort, Neufeld, and Edwards (1961) carried out a careful study, again of the uninjected pulmonary arteries, in fetuses and normal children. They measured medial thickness and external diameter and expressed these as a ratio: they also estimated medial area, relating 'the amount of muscle in the media' to the area of lung tissue in which it was found. They were able to show a rapid reduction in the amount of muscle tissue in the medial coat of the pulmonary arteries within the first two weeks after birth and thereafter a slower fall to the adult pattern over about 18 months. They thought that the rapid fall in medial thickness in the first two weeks of life might reflect the dilatation of the pulmonary arterial tree and decreasing vascular resistance, while they regarded as a true decrease in the medial coat that which continued gradually until the age of 18 months.

In normal children, Dammann and Ferencz (1956) described a decrease after birth in wall thickness of the muscle-containing pulmonary arteries. The thinning of the walls was most rapid in the first two to three months of life but continued for several more months. They measured the ratio of the wall thickness to the lumen diameter, but their arteries were not injected and therefore not distended.

The effect of dilatation of the pulmonary arteries in altering the wall thickness/external diameter ratio may be overcome by fully distending all vessels examined. In a study of the pulmonary arteries in normal adults, Elliott (1964; Elliott and Reid, 1965 ; Reid, 1967b) injected the arterial system with a quick-setting radio-opaque medium, thereby distending the arteries until the intimal elastic lamina of the wall was flattened. These authors were then able to compare directly the findings in different specimens. Their method has been followed in this series.

\section{RIGHT VENTRICLE}

In the months after birth when the pulmonary artery seems to be less muscular, the right ventricle, large at birth, is becoming smaller in relation to the left. This change is rapid, as was shown by Recavarren and Arias-Stella (1962), who weighed slices of the ventricles of normal children and found that the normal ratio of left to right ventricle was attained by the age of 4 months.

Fulton, Hutchinson, and Morgan Jones (1952) showed that the septum enlarged with the left ventricle. They dissected the two ventricles and weighed them separately: assessment of ventricular size can thus be assessed by absolute weight and by the ratio of left ventricle and septum to right ventricle. This method has been followed in this study.

As the precise methods developed by Elliott (1964) have not previously been applied to the child lung, the purpose of this study was to establish the growth in size and number of the pulmonary arteries during childhood and the distribution of muscle in their walls, to relate this pattern to alveolar development and to the weight of the right ventricle throughout childhood.

\section{MATERIALS AND METHODS}

The present study concerns eight lungs from five children: hearts were available from three of these children and four additional hearts were examined. The cases from whom lungs were obtained included a stillborn and ranged in age up to 11 years. The age, sex, cause of death and material examined are given in Table $I$. The lungs were received within 2 to 3 hours of removal from the body, and were

T A B L E I

MATERIAL EXAMINED

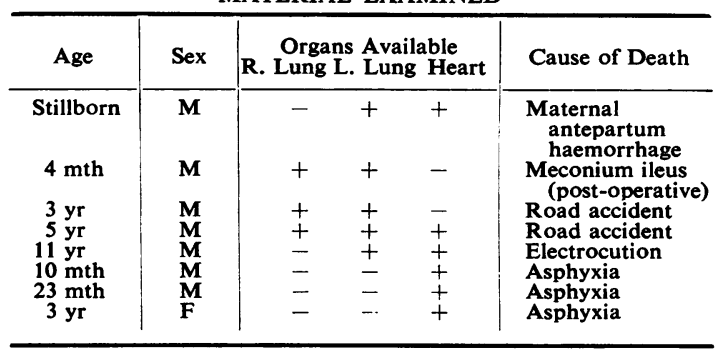


stored at $-20^{\circ} \mathrm{C}$. Before the pulmonary artery was injected the lungs were allowed to thaw at room temperature for 48 hours and were placed in an incubator at $37^{\circ} \mathrm{C}$. for one hour immediately before injection. This warming was essential for even injection and, while it did not interfere with arterial structure, in particular with identification of elastin and muscle fibres, it interfered with fine intracellular detail.

The pulmonary arterial system was injected with a mixture of gelatine and Micropaque (Damancy \& Co.) at $60^{\circ} \mathrm{C}$, and under a pressure of $100 \mathrm{~cm}$. water (Short, 1956; Elliott, 1964). This high pressure led to full distension of the pulmonary arteries down to a diameter of 15-25 $\mu \mathrm{m}$., but no medium entered the capillaries or veins. Unwanted artefacts were not produced, save in the lungs of the 11-year-old child, who died of electrocution: in these, in several places, the injection medium leaked into the alveolar spaces.

The lungs were inflated with buffered formalin introduced through the bronchial tree at a pressure of $75 \mathrm{~cm}$. of water. The formalin was allowed to flow until the pleural surfaces were tense, and then the airways were clamped. The lungs were allowed to float freely in liquid formalin for at least one week and lung volumes were then measured by water displacement. The volume of individual lobes was calculated later by macroscopic point-counting of the surface of lung slices.

\section{RADIOGRAPHY}

Radiographs of the lung were prepared on Kodirex non-screen film, using $45 \mathrm{kV}$ and $45 \mathrm{~mA}$, for 0.5 to 1.5 seconds at a tube distance of $70 \mathrm{~cm}$. The films were developed by the X-omat automatic process.

MEASUREMENTS FROM THE ARTERIOGRAMS The longest artery to the upper and lower lobes seen on the arteriogram was divided into 10 equal lengths, using waterproof ink to mark the film (see Fig. 1). The diameter of the artery at each point marked was measured as described by Millard (1965), excluding the two most proximal points where overlapping of arteries obscures the vessel edge. To increase the accuracy of the measurements, they were made with a dissecting microscope and a graticule unit was held in place across each artery.

SELECTION OF BLOCKS FOR MICROSCOPY The fixed lung was placed hilum upwards on a special cutting board and cut into slices, parallel to the hilum, with a sharp knife which was supported by Perspex runners on the edge of the board. In the larger lungs $1-\mathrm{cm}$. slices were cut, in the smaller $0.5-\mathrm{cm}$. The structures visible on the cut surface were analysed by pointcounting.

Blocks of tissue, each $2 \times 2 \mathrm{~cm}$. on the surface of the slice, were selected by stratified random sampling

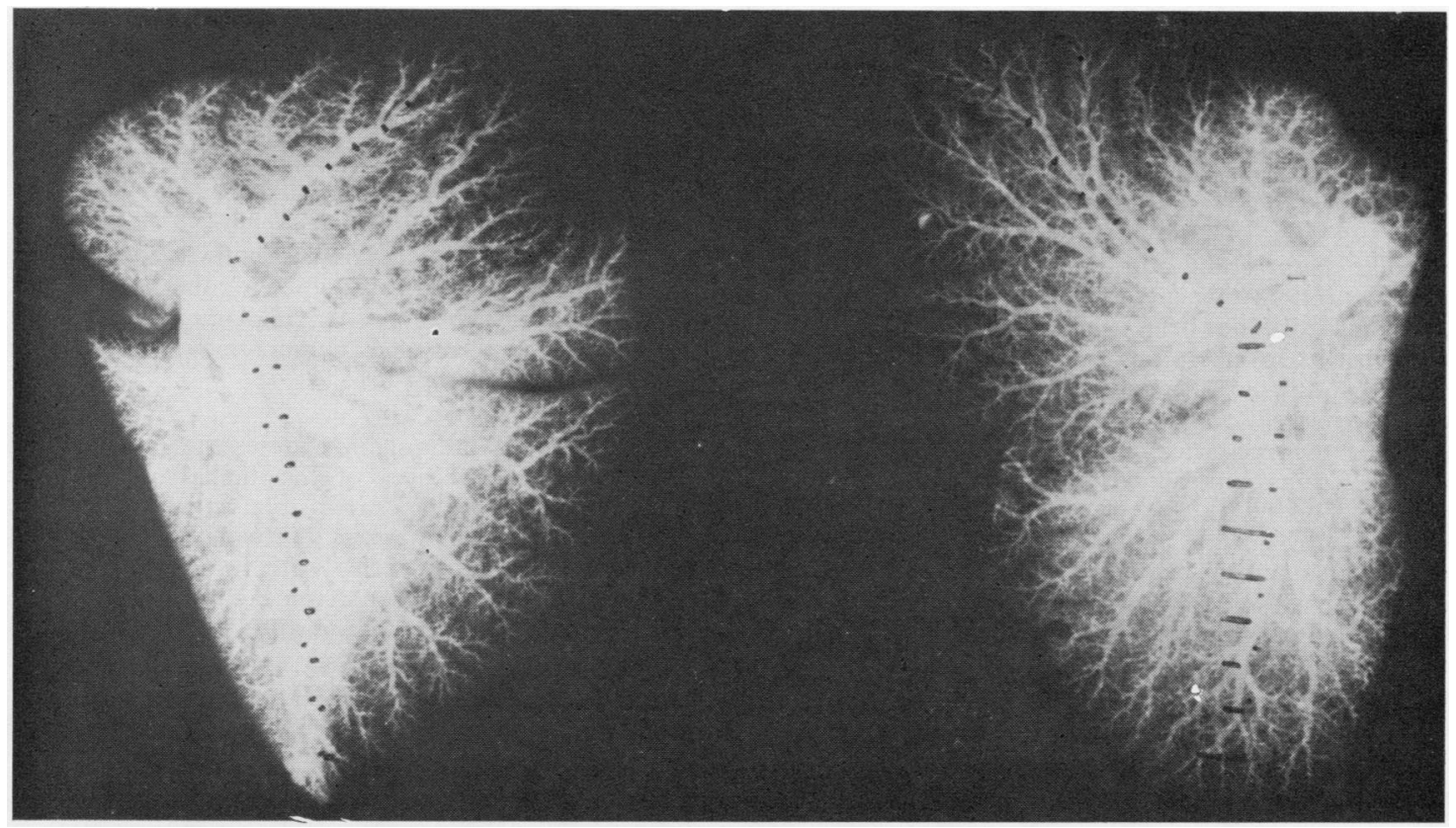

FIG. 1. Normal arteriogram of 3-year-old lungs (left lung to the left-hand of picture). Selected axial pathways marked at $10 \%$ of hilum to pleura distance, indicating the levels at which lumen diameter was measured (see Figs 2 and 3). 
and taken through the full thickness of the slice as described by Dunnill (1962a). As some of the lungs were so small that virtually the whole lobe was included in a few blocks, random sampling was not necessary in these lungs. In larger lungs a few extra blocks were taken from each lung to ensure that large arteries had been included.

The tissue was prepared routinely by dehydration in alcohol and then, after benzene treatment, was impregnated in wax. The blocks were cut so that the sections represented the whole of the tissue that had contributed to the cut surface. Sections were stained with Verhoeff's elastic stain and counter-stained by van Gieson's method.

\section{EXAMINATION OF THE HEART}

The heart was immersed in formalin for at least one week after its ventricular cavities had been opened to ensure adequate fixation. After this time Millard (1965) has shown that there is no significant fall in weight. The heart was then dissected in the manner described by Fulton and his colleagues (1952) and the left ventricle and septum were weighed separately from the free wall of the right ventricle. The ratio

\section{left ventricle + septum right ventricle}

was calculated. In normal adults these authors found that this ratio lay between $2 \cdot 3$ and $3 \cdot 3: 1$.

ALVEOLAR NUMBER The alveoli were counted by the method of Weibel and Gomez (1962). Corrections were made for shrinkage of tissue due to dehydration and mounting of the sections. On three lungs the counts were repeated at intervals as a check of the accuracy of the method.

ALVEOLAR SIzE Dunnill (1962a) estimated a mean alveolar diameter by choosing typical looking alveoli to measure ; as this method must be open to subjective error it has not been used. Since the mean alveolar size must be inversely related to the number of alveoli in a millilitre of lung tissue, and since this value emerges during the calculation of alveolar number, the reciprocal of this value multiplied $\times 10^{6}$ was taken as an indication of individual alveolar volume. This figure rises as the alveolar size increases.

ALVEOLAR SHAPE The number of intercepts made with alveolar walls by a randomly orientated line of known length increases with increasing complexity and folding of the alveolar walls, and decreases as the alveoli grow larger. The mean linear intercept (Dunnill, 1962a) was here adjusted for alveolar size by dividing the intercept number by the number of alveoli in a square centimetre of lung tissue; the resulting figure is a reflection of the degree of complexity of the alveolar walls. The figure so obtained has been multiplied by $10^{3}$ to obtain numbers of a convenient order.

\section{PULMONARY ARTERY MEASUREMENTS}

TERMS USED IN DESCRIBING PULMONARY ARTERIES Passing to the periphery of any arterial pathway the complete muscular coat is replaced by a spiral of muscle before the muscle disappears. These three regions have been described as muscular, partially muscular and non-muscular respectively (Elliott, 1964; Reid, 1967b). In cross-section non-muscular arteries are those with no muscle tissue visible in their walls; partially muscular arteries are those in which the muscle coat is interrupted so that at least some part of the circumference is free of muscle.

EXTERNAL DIAMETER AND WALL THICKNESS Along one diameter, external diameter was measured between and including the two external elastic laminae. The medial or wall thickness was measured on the same diameter and included the internal and external laminae, when present, as well as the muscle.

Most authors have avoided arteries cut in oblique section, but consideration of an oblique section of a tube shows that the shortest diameter is the same as the diameter in a cross-section at right angles to the longitudinal axis. It is also seen that the wall thickness at the level of the shortest diameter is the same as that in true cross-section. Obliquely sectioned arteries have therefore not been avoided, but measurements have been made only in one plane, across the minor diameter.

The thickness of the muscular coats has been expressed as a percentage of the external diameter as follows

Percentage wall thickness $(\% \mathrm{WT})=$

$$
\frac{2 \times \text { wall thickness }}{\text { external diameter }} \times 100
$$

ARTERIES PER UNIT AREA The concentration of arteries within the lung was assessed by counting arteries between 25 and $200 \mu \mathrm{m}$. external diameter in a series of microscopic fields each $6 \mathrm{~mm}^{2}$ in area, hereafter referred to as the 'unit area'.

MEDIAL AREA If pulmonary arteries are not injected, measurement of the area of the medial or muscular coat has the advantage that it does not vary with the degree of distension, whereas the wall thickness does. As the arteries in this series were fully distended the measurement of medial area for each artery has little to offer that is better than wall thickness measurement. Wagenvoort (1960) used a measure of arterial muscular or medial area per unit area of section, and argued that an increase in this value showed a true increase in muscle mass. A modification of this measurement has been used here to relate arterial muscularity to unit area of lung. The medial area of an average artery in each size range from 25 to $200 \mu \mathrm{m}$. was multiplied by the number of arteries in that range. Allowance was made for partially muscular 
T A B L E II

NORMAL LUNG AND LOBAR VOLUME (ml.)

\begin{tabular}{|c|c|c|c|c|c|c|c|c|c|}
\hline \multirow{2}{*}{\multicolumn{2}{|c|}{ Age }} & & \multirow{2}{*}{ Right Lung } & \multicolumn{3}{|c|}{ Lobes } & \multirow{2}{*}{ Left Lung } & \multicolumn{2}{|c|}{ Lobes } \\
\hline & & & & Upper & Middle & Lower & & Upper & Lower \\
\hline Stillborn & . & . & - & - & - & - & 23 & $\begin{array}{c}9 \\
(0.39)\end{array}$ & $\begin{array}{c}14 \\
(0.61)\end{array}$ \\
\hline $4 \mathrm{mth}$ & & . & 115 & $\begin{array}{c}39 \\
(0 \cdot 34)^{1}\end{array}$ & $\begin{array}{c}24 \\
(0 \cdot 21)\end{array}$ & $\begin{array}{c}52 \\
(0.45)\end{array}$ & 108 & & $\begin{array}{c}71 \\
(0.66)\end{array}$ \\
\hline $3 \mathrm{yr}$ & $\cdots$ & $\cdots$ & 200 & & $\begin{array}{c}37 \\
(0 \cdot 18)\end{array}$ & $\begin{array}{c}95 \\
(0.48)\end{array}$ & 184 & $\begin{array}{c}79 \\
(0.43)\end{array}$ & $\begin{array}{l}105 \\
(0.57)\end{array}$ \\
\hline $5 \mathrm{yr}$ & $\cdots$ & $\cdots$ & 625 & $\begin{array}{c}197 \\
(0.32)\end{array}$ & $\begin{array}{c}109 \\
(0 \cdot 17)\end{array}$ & $\begin{array}{c}319 \\
(0.51)\end{array}$ & 560 & $\begin{array}{c}270 \\
(0.48)\end{array}$ & $\begin{array}{c}290 \\
(0.52)\end{array}$ \\
\hline $11 \mathrm{yr}$ & . & $\cdots$ & 一 & - & - & - & 925 & $\begin{array}{c}420 \\
(0.45)\end{array}$ & $\begin{array}{c}505 \\
(0.55)\end{array}$ \\
\hline
\end{tabular}

Figures in parentheses refer to the portion of the lung comprised by the given lobe.

arteries by assuming that the average partially muscular artery has muscle about $50 \%$ of its circumference. The total area of muscular media of all arteries up to $200 \mu \mathrm{m}$. in external diameter was then calculated per unit area.

POPULATION COUNTS In a given area of section all arteries were measured and classed as non-muscular, partially muscular or wholly muscular. Enough fields were examined to allow each type to be calculated at each diameter range; this meant that several hundred arteries were included. The limiting diameter for each type of artery is then apparent.

ARTERIES RUNNING WITH TERMINAL AND RESPIRATORY BRONCHIOLI The 'land-marking' of arteries in the lungs by reference to their accompanying airways was suggested by O'Neal, Thomas, and Hartroft (1955). Elliott (1964) and Reid (1967b) showed in the adult lung that the range of diameters of vessels accompanying a given type of airway is quite large, so that arteries are less precisely described by 'landmarking' than by reference to their external diameter.

In the child lung, where new arteries are increasing in size, it is valuable to take into account the level of an artery in its pattern of branching as well as its structure and external diameter. If 'land-marking' by airways is to be used, a mean size must be calculated from a large number of vessels. Respiratory bronchioli can be identified on a single section and the associated terminal bronchiolus may, less often, be found included in the same section. Many fields were searched for these airways and the accompanying arteries were measured and also classed as wholly, partially or non muscular.

\section{RESULTS}

\section{LUNG AND LOBAR VOLUMES}

The normal lung volumes are shown in Table II as well as the approximate volume of the individual lobes as estimated by point-counting. If all segments in the lungs of any individual are taken as being of the same volume, then the rela- tive volumes of the lobes could be predicted by the number of segments in each lobe. The ratio of lobar volumes in the right lung would be, upper middle to lower lobe $0 \cdot 3: 0 \cdot 2: 0 \cdot 5$, and in the left lung, upper to lower lobe $0 \cdot 5: 0 \cdot 5$. In the right lung of the subjects aged 4 months and 3 and 5 years, these ratios were nearly attained so that lobar size was roughly proportional to the number of segments in each lobe. In the left, in all five cases the lower lobe was consistently larger than the upper, although this was less striking in the larger lungs. In the three instances when both lungs were available, the left was smaller than the right, being 93,92 and $90 \%$ of the volume of the right lung in subjects 2,3 and 4 respectively.

\section{ALVEOLAR MEASUREMENTS}

The number of alveoli found in each lung, the mean number of alveoli in $1 \mathrm{ml}$. of lung tissue and the figure expressing mean alveolar complexity are shown in Table III.

T A B L E I I I

ALVEOLAR MEASUREMENTS

\begin{tabular}{|c|c|c|c|c|c|}
\hline & & & $\begin{array}{l}\text { Alveolar No. } \\
\qquad\left(\times 10^{6}\right)\end{array}$ & $\underset{\left(\times 10^{6}\right)}{\text { Alveoli } / \mathrm{ml}}$ & $\begin{array}{c}\text { Index of } \\
\text { Alveolar } \\
\text { Complexity } \\
\text { (intercept } \\
\text { count } \times 10^{3} \\
\text { alveoli } / \mathrm{cm}^{2} \text { ) }\end{array}$ \\
\hline $\begin{array}{l}\text { Stillborn. } \\
4 \mathrm{mth} \\
3 \mathrm{yr} \\
5 \mathrm{yr} \\
11 \mathrm{yr}\end{array}$ & $\begin{array}{l}\cdots \\
\cdots \\
\cdots\end{array}$ & $\begin{array}{l}\ddot{ } \\
\ddot{y} \\
\ddot{*}\end{array}$ & $\begin{array}{l}17 \cdot 25^{1} \\
76 \cdot 7 \\
196 \\
303 \\
336^{1}\end{array}$ & $\begin{array}{l}1 \cdot 01 \\
0 \cdot 785 \\
0 \cdot 787 \\
0 \cdot 548 \\
0 \cdot 388\end{array}$ & $\begin{array}{l}4 \cdot 5 \\
3 \cdot 4 \\
3 \cdot 8 \\
4 \cdot 1 \\
5 \cdot 7\end{array}$ \\
\hline
\end{tabular}

${ }^{1}$ Figure given as for both lungs although only one counted

ALVEOLAR NUMBER The counts in the 3-year-old child, obtained on four different occasions, were $200 \times 10^{6}, 195 \times 10^{6}, 201 \times 10^{6}$ and $188 \times 10^{6}$. In the 5-year-old child, on three occasions, the counts were $298 \times 10^{6}, 295 \times 10^{6}$ and $316 \times 10^{6}$. In the 11-year-old child the left lung only was counted 
on two occasions- $160 \times 10^{6}$ and $176 \times 10^{6}$. In each case the average has been recorded in Table III. This variation would seem acceptable.

The numbers obtained are some $10 \%$ above those reported by Dunnill (1962b). The discrepancy probably arises from the practical difficulty of identifying an alveolus. Boyden (1965) has shown that the alveoli at birth have not the structure of true alveoli. Dunnill's convention, even after discussion with him, gave consistently higher results than he obtained but the general pattern of increase reported here is similar to his.

ALVEOLAR SIZE AND SHAPE Throughout childhood the mean number of alveoli in $1 \mathrm{ml}$. of lung tissue decreases, pointing to an increase in alveolar size. There is little difference between the lung of the 4-month-old and the 3-year-old child: by 5 years the number of alveoli $/ \mathrm{ml}$. lung tissue has fallen, and is even lower by 11 years. This suggests that during the period of most rapid multiplication the alveoli alter little in size. From the age of 4 months onwards the index of alveolar complexity increases, suggesting that the alveoli are growing more complex in outline even as the diameter of each is increasing.

\section{MEASUREMENTS OF THE PULMONARY ARTERIES}

ARTERIOGRAMS Filling in the periphery of the pulmonary arteriogram appears less dense in the younger lungs than in the adult. This means that there are fewer vessels large enough to be detected as individual lines and also fewer small vessels to give a background haze. In the 3-year-old lung peripheral arterial filling is much increased when compared with the 4-r-onth-old child, suggesting a rapid multiplication of new arteries during this period.

Lumen diameters at successive $10 \%$ intervals of the longest pulmonary arteries, as seen on the arteriogram of both upper and lower lobes, are shown in Figures 2 and 3.

Generally speaking, with increasing age the arteries became larger at all levels, although there was little difference between the 3- and 5-year-old. Between birth and 11 years the proximal part of the artery increased 4- to 5-fold in the upper lobe and 3-fold in the lower lobe; the distal part 5-fold in diameter in the upper lobe and 3-fold in the lower lobe. The relative increase centrally and peripherally was similar for each lobe. The rate of narrowing of the arteries, as seen from the gradient of the lines, was relatively faster over the central or larger parts of the arteries, and in the

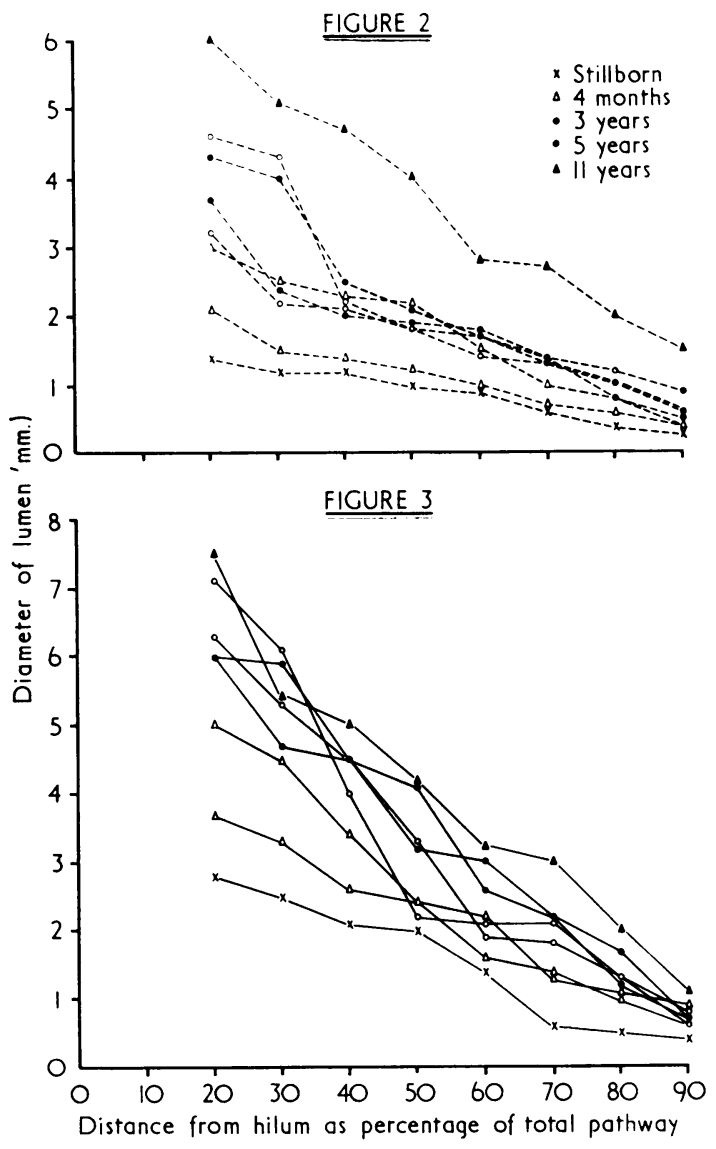

FIG. 2. Lumen of upper lobe axial pathway measured in arteriogram at various ages. Centrally and peripherally a five-fold increase in diameter is found.

FIG. 3. Lumen of lower lobe axial pathway measured in arteriogram at various ages. Centrally and peripherally a three-fold increase in diameter is found.

lower lobes than in the upper lobes, reflecting the larger diameters of the lower lobar arteries near the hilum.

NUMBER OF SMALL ARTERIES IN UNIT AREA OF LUNG The number of arteries between 25 and $200 \mu \mathrm{m}$. in diameter in a unit area of lung section is shown at different ages in Figure 4. There was a striking increase in the number of arteries in each size range between the ages of 4 months and 3 years. Thus, in addition to the overall increase in lung volume, there is an increase in arterial concentration for unit area between these ages, confirming the appearance in the arteriograms. In the 5and 11-year-old children the number of arteries 


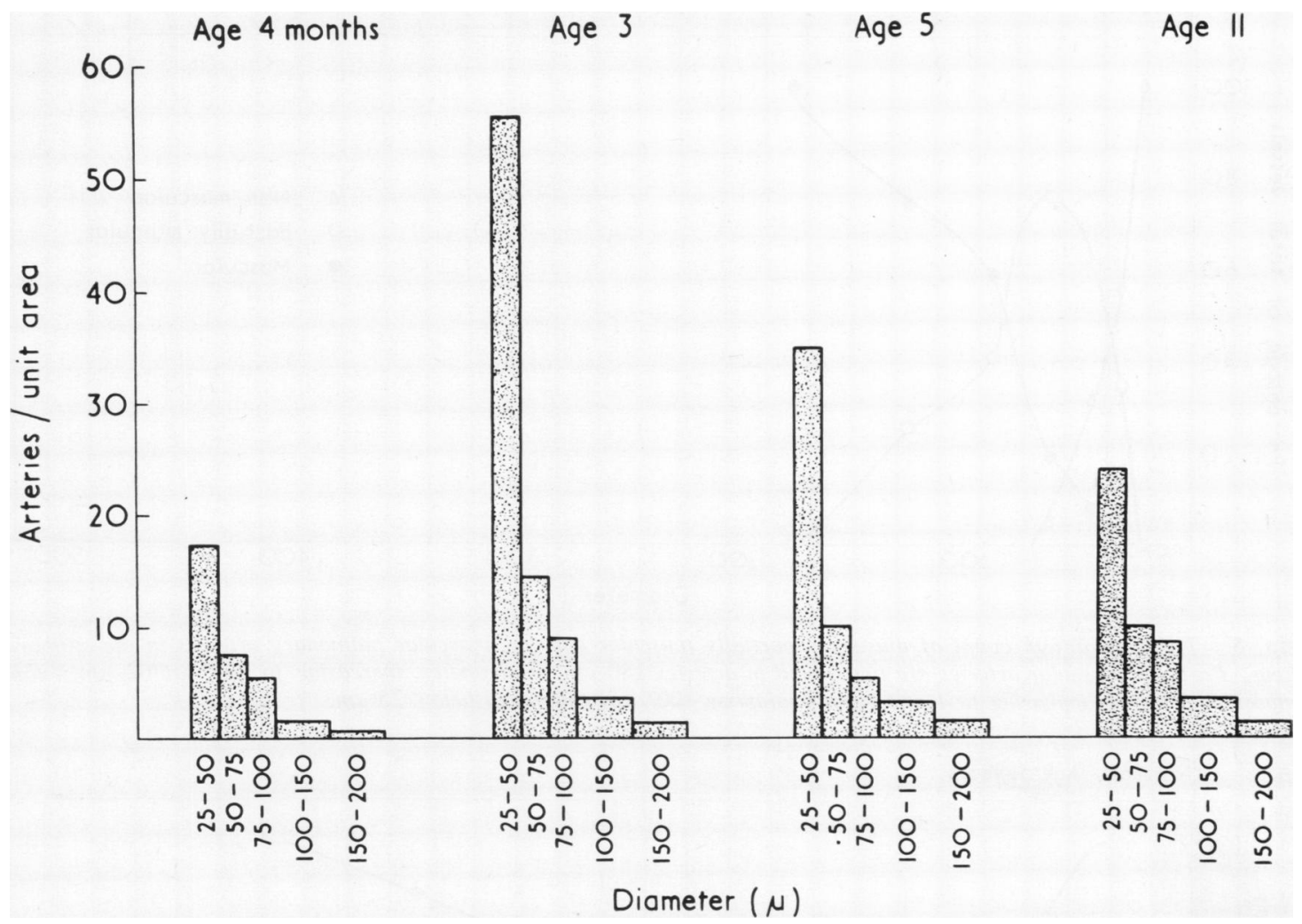

FIG. 4. Distribution of arteries below $200 \mu \mathrm{m}$. per unit area of lung at four ages. Between 4 months and 3 years a great increase is seen associated with alveolar multiplication: the number later falls with increase in alveolar size.

T A BLE I V

SIZE RANGE $(\mu \mathrm{m}$.) OF MUSCULAR, PARTIALLY MUSCULAR AND NON-MUSCULAR ARTERIES IN THE NORMAL CHILD LUNG

\begin{tabular}{|c|c|c|c|c|c|c|c|c|}
\hline & & & Stillborn & $4 \mathrm{mth}$ & $3 \mathrm{yr}$ & $5 \mathrm{yr}$ & $11 \mathrm{yr}$ & $19 \mathrm{yr}^{1}$ \\
\hline $\begin{array}{l}\text { Largest non-muscular } \\
\text { Range of partially muscular } \\
\text { Smallest muscular } \ldots\end{array}$ & $\begin{array}{l}\ddot{*} \\
\ddot{*}\end{array}$ & $\begin{array}{l}\cdots \\
\cdots\end{array}$ & $\begin{array}{c}62 \\
27-180 \\
42\end{array}$ & $\begin{array}{c}130 \\
75-190 \\
90\end{array}$ & $\begin{array}{c}200 \\
100-300 \\
160\end{array}$ & $\begin{array}{c}240 \\
120-380 \\
200\end{array}$ & $\begin{array}{c}180 \\
50-360 \\
100\end{array}$ & $\begin{array}{c}120 \\
30-130 \\
30\end{array}$ \\
\hline
\end{tabular}

1Data from Elliott (1964)
The italic figures give the largest artery at which muscle is discontinuous. For arteries below this size, distribution studies of the total artery 'population' are necessary.

in each size range fell somewhat. This doubtless arises from the fact that the alveoli were larger and the alveolar walls, in which these small vessels lie, were further apart.

SIZE RANGE OF TYPES OF ARTERY AND POPULATION counTs In Table IV is shown the diameter range for three types of pulmonary artery, nonmuscular, partially muscular and wholly muscular. These figures can be derived from the population distribution graphs for the children, as illustrated in Figures 5 and 6. Elliott (1964) included in his work the population figures in a normal 19-yearold boy. His results have been confirmed by one of us (G. D.) on the same specimen and are here taken as the values for the normal young adult.

In the stillborn child a mixed arterial population appeared first at $180 \mu \mathrm{m}$., with muscle being found in arteries as small as $27 \mu \mathrm{m}$. in external diameter. The smallest wholly muscular artery was $42 \mu \mathrm{m}$. in diameter, and the largest nonmuscular artery $62 \mu \mathrm{m}$. Up to the age of 11 years 
Stillborn.

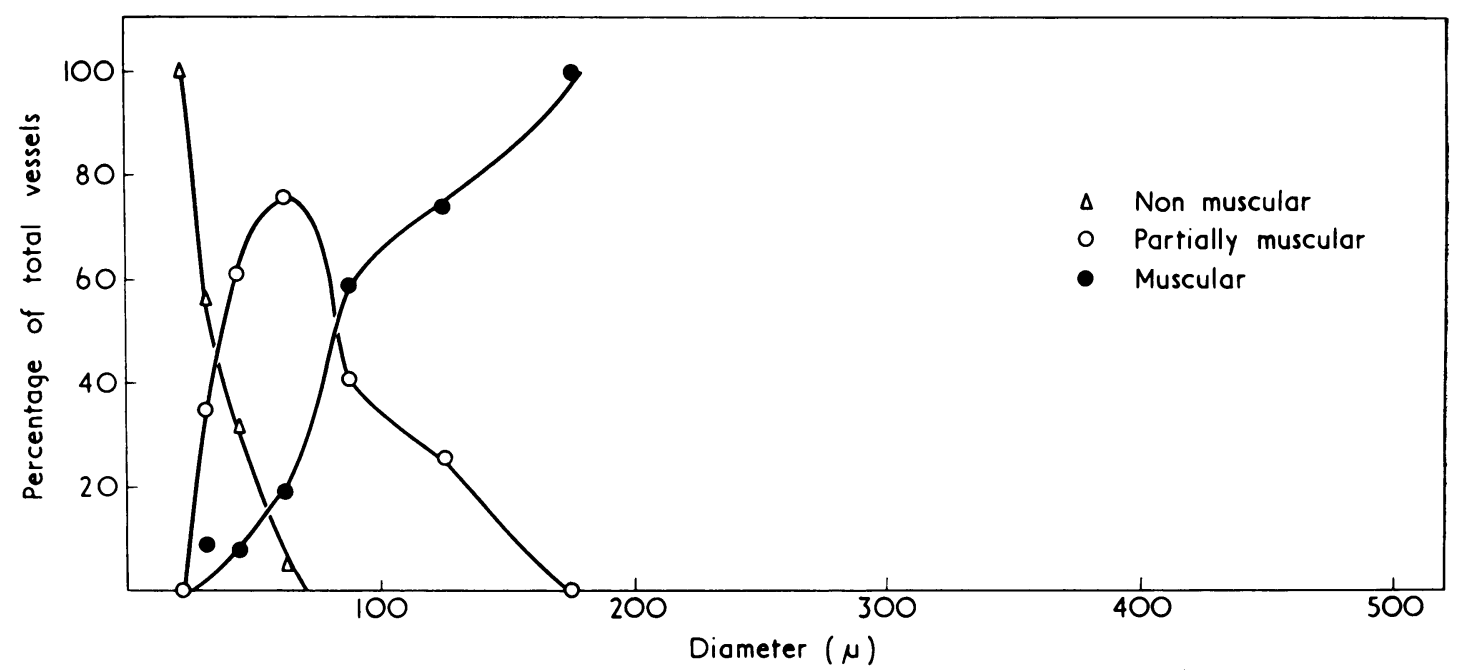

FIG. 5. The 'population' count of muscular, partially muscular and non-muscular pulmonary arteries in the stillborn lung. Partially muscular arteries are first found in arteries $180 \mu \mathrm{m}$. in diameter, increasing to $76 \%$ at $62 \mu \mathrm{m}$.: nonmuscular arteries, appearing first at $62 \mu \mathrm{m}$., comprise $100 \%$ of the group below $25 \mu \mathrm{m}$.

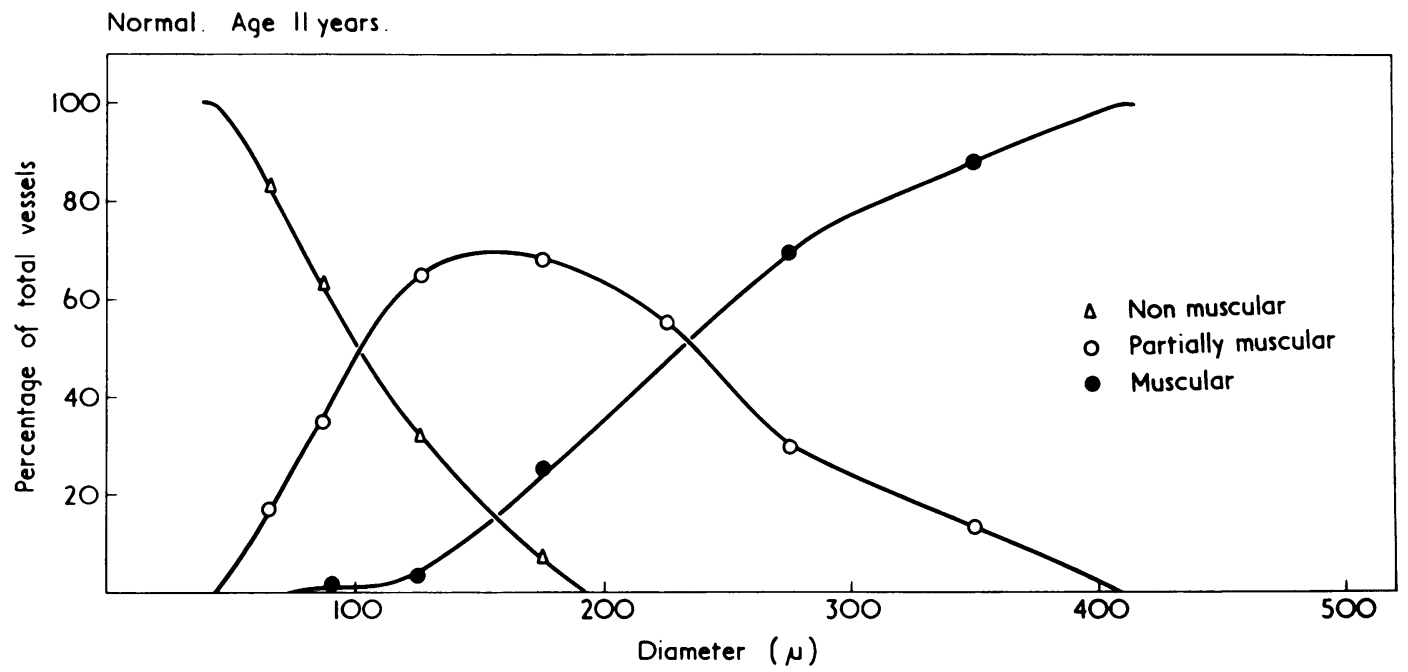

FIG. 6. As Fig. 5 for the 11-year child showing that partially and non-muscular structure is found in much larger arteries. By $90 \mu \mathrm{m}$. all arteries are non-muscular.

the transition to a mixed arterial population appears in progressively larger arteries. The curves have extended to the right until, at the age of 11 , the partially muscular wall structure now appears in arteries of $360 \mu \mathrm{m}$. external diameter, while non-muscular arteries are as large as $180 \mu \mathrm{m}$. This means that muscle does not extend into such small arteries as at birth.
In the adult, Elliott shows that muscle is again to be found in arteries nearly as small as at birth; therefore, throughout early childhood muscle $\stackrel{\mathcal{D}}{?}$ tissue apparently is only found in larger arteries, but between 11 and 19 years this trend is reversed. PERCENTAGe Wall thickness (\%Wt). The percentage wall thickness over the age range studied 


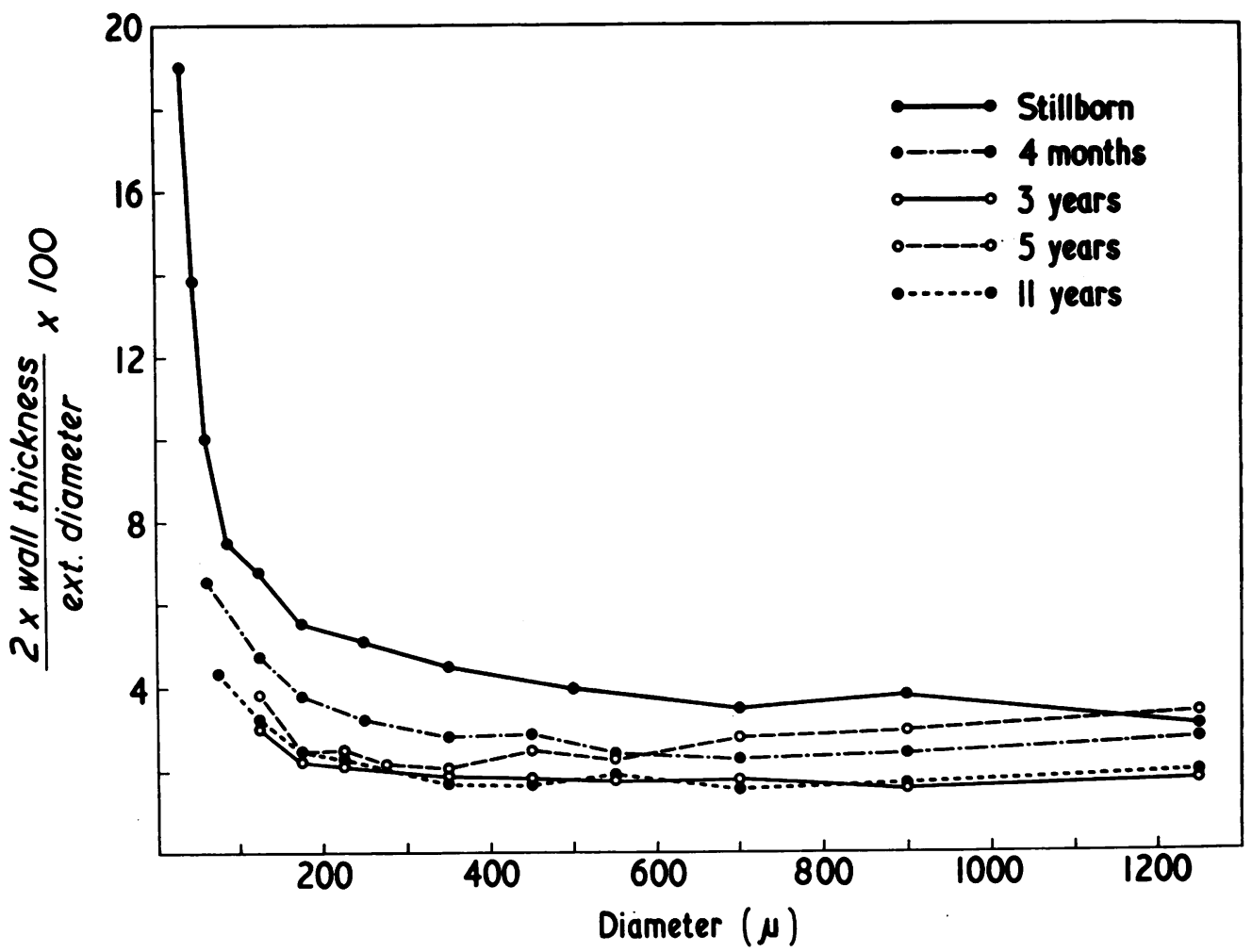

FIG. 7. Thickness of the pulmonary artery medial coat at birth and throughout childhood. The adult values are reached at 4 months; at 3 to 5 years muscle does not penetrate into such small arteries as at the other ages shown.

is shown in Figure 7. At all ages a rise in percentage wall thickness is seen in the small arteries. In the stillborn child the smallest muscle-containing arteries had a mean percentage wall thickness as high as $19.2 \%$. By $200 \mu \mathrm{m}$. in diameter the mean value for wall thickness was 4.5 to $5 \%$, while near the lobar hilum it was $3.5 \%$, a value within the normal adult range.

In none of the older children was muscle found in such small arteries and, when found, constituted less of the diameter. The smallest arteries containing muscle in the 4-month-old child had a mean percentage wall thickness of 6.8 and, by the age of 3 years, this figure was $3 \cdot 0$. The wall thickness of the mid-lung vessels was lower, and had fallen to the near adult values of 2 to $3 \%$ (Elliott, 1964) by the age of 4 months. In the three older children the mean values at all levels were within the normal adult range.

This shows that the 'thinning' of the walls of the pulmonary arteries relative to their external diameter takes place rapidly after birth, being nearly complete by the age of 4 months. This process occurs at much the same rate as the decrease, described later, in right ventricular size relative to the left.

INDEX OF MEDIAL AREA The medial area of all arteries between 25 and $200 \mu \mathrm{m}$. in diameter in a unit area of lung was, at 4 months, $4,949 \mu \mathrm{m} .{ }^{2}$ / $\mathrm{mm}^{2}$ : this dropped progressively to $2,265 \mu \mathrm{m} .{ }^{2} /$ $\mathrm{mm} .{ }^{2}$ at 3 years, and to $1,052 \mu \mathrm{m} .{ }^{2} / \mathrm{mm}^{2}{ }^{2}$ at 5 years : by 11 years it had risen to $5,029 \mu \mathrm{m}^{2} / \mathrm{mm}^{2}$. The early decrease reflects the absence of muscle in small arteries, and the increase at 11 years reflects its progressive extension into the acinus in later childhood.

TYPE OF ARTERY WITH TERMINAL AND RESPIRATORY BRONCHIOLI Table $\mathrm{V}$ and Fig. 8 show the mean diameters and range of the arteries running with terminal and respiratory bronchioli, and the percentage of each group which have partially muscular walls. With age, the arteries at each of these levels grow in external diameter, the range 
T A B L E V

MEAN DIAMETER AND SIZE RANGE OF ARTERIES $(\mu \mathrm{m}$.) ACCOMPANYING TERMINAL AND RESPIRATORY BRONCHIOLI IN THE NORMAL CHILD LUNG

\begin{tabular}{|c|c|c|c|c|c|c|c|c|c|}
\hline Arteries Accompanying & & & & Stillborn & $4 \mathrm{mth}$ & 3 yr & 5 yr & $11 \mathrm{yr}$ & $19 \mathrm{yr}^{1}$ \\
\hline $\begin{array}{l}\text { Terminal bronchioli } \\
\text { Mean diameter } \quad \ldots \\
\text { Range . } \\
\text { Partially muscular }(\%)\end{array}$ & $\begin{array}{l}\ldots \\
\cdots \\
\cdots\end{array}$ & $\begin{array}{l}\cdots \\
\cdots \\
\cdots\end{array}$ & $\begin{array}{l}\cdots \\
\cdots \\
\cdots\end{array}$ & $\begin{array}{c}68 \\
40-101 \\
44\end{array}$ & $\begin{array}{c}160 \\
87-296 \\
5\end{array}$ & $\begin{array}{c}285 \\
172-380 \\
2\end{array}$ & $\begin{array}{r}400 \\
325-600 \\
0\end{array}$ & $\begin{array}{c}475 \\
300-705 \\
0\end{array}$ & $\begin{array}{r}582 \\
372-976 \\
0\end{array}$ \\
\hline $\begin{array}{l}\text { Respiratory bronchioli } \\
\text { Mean diameter .. } \\
\text { Range . } \\
\text { Partially muscular }(\%)\end{array}$ & $\begin{array}{l}\ldots \\
\cdots \\
\cdots\end{array}$ & $\begin{array}{l}\ldots \\
\therefore \\
\cdots\end{array}$ & $\begin{array}{l}\cdots \\
\cdots \\
\cdots\end{array}$ & $\begin{array}{c}43 \\
31-72 \\
83\end{array}$ & $\begin{array}{c}95 \\
53-168 \\
65\end{array}$ & $\begin{array}{c}160 \\
87-296 \\
74\end{array}$ & $\begin{array}{c}260 \\
73-404 \\
50\end{array}$ & $\begin{array}{c}305 \\
176-450 \\
28\end{array}$ & $\begin{array}{c}341 \\
203-565 \\
0\end{array}$ \\
\hline
\end{tabular}

Data from Elliott (1964)

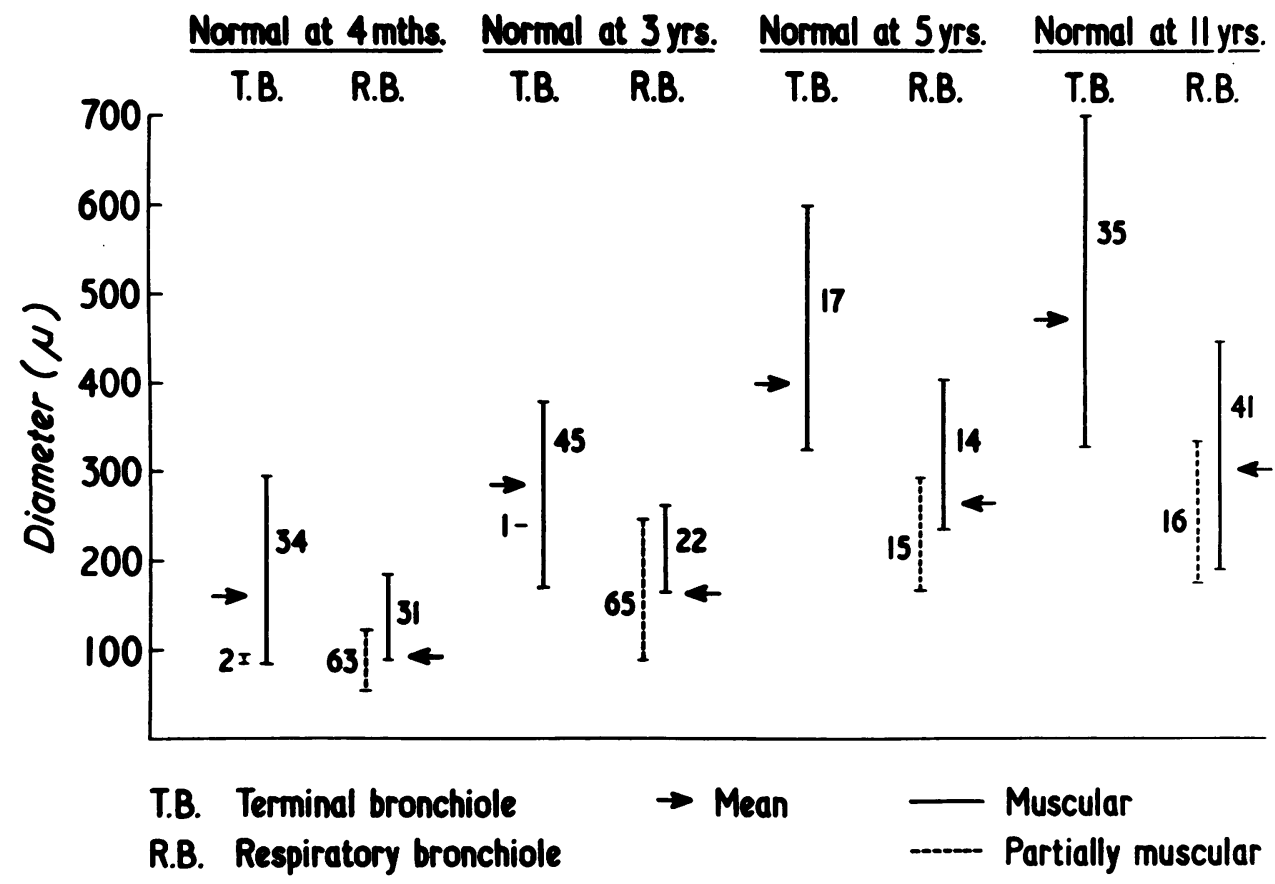

FIG. 8. The diameter range and distribution of muscular and partially muscular pulmonary arteries in arteries running with terminal and respiratory bronchioli, at selected ages. The figure alongside the diameter range indicates the number of arteries examined.

of arterial diameter found in each group is seen to widen and there is progressive muscularization.

At birth $56 \%$ of the arteries running with terminal bronchioli are muscular, the rest being partially muscular. By the age of 4 months the percentage of muscular arteries has increased, and, by the age of 5 years, all are wholly muscular as in the adult. At birth, of the arteries running with respiratory bronchioli only $17 \%$ are muscular, and the rest are partially muscular. The percentage of muscular arteries increases less rapidly in this group, but by 11 years it is $72 \%$ and by 19 years all are muscular.

\section{RIGHT VENTRICULAR WEIGHT}

In Table VI are shown the results from seven normal children for the weight of the free wall of the right ventricle and of the left ventricle and septum together as well as the ratio. The ratio in the stillborn child indicates the relative preponderance of the right ventricle at birth. By the 
T A B LE V I

NORMAL VENTRICULAR WEIGHTS (g.)

\begin{tabular}{|c|c|c|c|c|}
\hline Age & & $\begin{array}{c}\text { Left } \\
\text { Ventricle }\end{array}$ & $\begin{array}{c}\text { Right } \\
\text { Ventricle }\end{array}$ & $\mathbf{L V}+\mathbf{S}$ \\
\hline 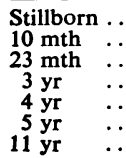 & $\begin{array}{l}\ldots \\
\ddot{0} \\
\cdots \\
\cdots \\
\ldots\end{array}$ & $\begin{array}{l}6 \cdot 7 \\
20 \cdot 5 \\
27 \cdot 5 \\
26 \cdot 7 \\
35 \cdot 8 \\
59 \cdot 4 \\
94\end{array}$ & $\begin{aligned} 5 \cdot 6 \\
7 \cdot 6 \\
9 \cdot 1 \\
10 \cdot 3 \\
13 \cdot 7 \\
18 \cdot 3 \\
36\end{aligned}$ & $\begin{array}{l}1 \cdot 20 \\
2 \cdot 89 \\
2 \cdot 81 \\
2 \cdot 59 \\
2 \cdot 61 \\
3 \cdot 25 \\
2 \cdot 61\end{array}$ \\
\hline
\end{tabular}

age of 10 months the adult ratio (between $2 \cdot 3$ and $33 \cdot 1: 1$ ) has been attained, and this ratio is found throughout childhood.

\section{DISCUSSION}

\section{ALVEOLAR DEVELOPMENT}

Multiplication of the alveoli in childhood was first described by Willson (1928). He noticed on uninflated sections of lung tissue that the alveoli in a 13-year-old child were smaller than those in children under the age of 7 years, and deduced that there must be more alveoli in the older child. The growth in alveolar size reported here to occur after the age of 3 years appears, at first sight, to contradict the findings of Willson (1928). The explanation probably lies in the preparation of the tissue: the lungs in our series were inflated to the fullest extent possible before fixation, whereas those in Willson's case were not inflated.

The rate of growth of the alveoli has been well described by Dunnill (1926b), whose methods we have used here. The alveolar number reported here is, at all ages, somewhat higher than Dunnill's, but the pattern of growth is similar, confirming that the most rapid multiplication of the alveoli occurs in the first three years of life.

Dunnill (1962b) found in children that alveolar surface area increased with age and showed a linear relationship to body surface area. The increase in complexity of shape of the alveoli from the age of 4 months indicates that the surface area of the alveoli increases more rapidly than the alveolar number.

\section{GROWTH IN SIZE AND NUMBER OF PULMONARY ARTERIES}

Measurement of the lumen diameters of the pulmonary arteries as seen in the arteriogram provides an indication of their rate of growth throughout childhood. It seems that the upper lobe artery grows in diameter more rapidly than the lower; for example, between birth and 11 years there is a 25 -fold increase in cross-sectional area. In the lower the increase in cross-sectional area is nine-fold.

The rate of growth of the pulmonary arteries in external diameter may be seen from the increase in size of the arteries accompanying distal airways. The true increase in diameter is masked to some degree by the change in type of the last two or so generations of bronchioli in the first three years of life (Boyden, 1965). This means that some of the arteries running with terminal bronchioli at birth will later come to accompany respiratory bronchioli, with the effect that a larger artery will come to accompany the latter.

It is unlikely that this 'alveolization' of bronchioli continues after the age of 3 years (Boyden, personal communication), as bronchial generation counts in fetal and adult life show a reduction of not more than two generations of non-respiratory bronchioli (Bucher and Reid, 1961). The increase in size of the arteries accompanying respiratory bronchioli, certainly after the age of 3 years, probably represents therefore a true growth in diameter.

On inspection of the arteriogram, increase in background opacity, particularly between the ages of 4 months and 3 years, probably reflects the increase in the number of small pulmonary arteries. The actual number of small arteries is difficult to measure directly, but the number of small intra-acinar arteries in a unit area of lung may be shown to increase sharply between these ages, and this must represent a rapid growth of new arteries. Arterial generation counts in the fetus have shown that the full number of preacinar arterial branches is present at birth (Hislop, 1969) so that thereafter multiplication of the pulmonary arteries is confined to the intra-acinar branches.

\section{DisTRIBUTION OF MUSCLE IN THE PULMONARY ARTERIES IN CHILDHOOD}

In the newborn child, muscle is found in the media of very small arteries-as small as $27 \mu \mathrm{m}$. in diameter. The arterial walls are thick, especially in the smaller vessels. The artery supplying an acinus may be either partially muscular or wholly muscular, so that with non-respiratory airways some arteries with incomplete muscular coats are found.

As the child grows it seems that the muscle tissue 'recedes' into larger arteries. This could be due to atrophy of muscle or to growth in artery size without new muscle formation. Since, 
during this period, the arteries accompanying terminal and respiratory bronchioli become more muscular in type, it appears improbable that there is atrophy of arterial muscle. The 'alveolization' of terminal bronchioli described by Boyden (1965) in the first three years of life may account for the apparent increase of muscle tissue in these arteries, so it remains uncertain whether or not new muscle is appearing in the pulmonary arteries in the first few years of life.

By the age of 5 years larger arteries are still found without muscle, but because of the growth in volume of the lung some muscle tissue is found in arteries within the acinus. Indeed, by now all arteries accompanying non-respiratory airways have a completely muscular coat. Within the acinus quite large arteries, up to $240 \mu \mathrm{m}$. in diameter, have no muscle in their wall. This slow extension proceeds throughout childhood and adolescence, until by adult life (Elliott, 1964) muscle has extended into arteries as small as in the fetus, although these are now much further into the acinus than is the case in the newborn child.

The thick walls of the pulmonary arteries in the newborn rapidly become thinner, and by the age of four months have nearly reached adult levels. This may mean that arteries have increased in diameter without a corresponding increase in muscle (Wagenvoort et al., 1961), but some of the apparent thinning may be, as these authors suggested, due to dilatation of the pulmonary arteries in the first few weeks after birth. A reduction in weight of the right ventricle has been reported after birth (Keen, 1955). This probably reflects the fall in pulmonary vascular resistance that occurs at birth. It may be that reduction in arterial tone, which is presumably associated with this, leads to atrophy of arterial muscle.

\section{THE RIGHT VENTRICLE IN CHILDHOOD}

At birth the ratio of left ventricular + septal weight to the right ventricular weight was low, showing a relatively large right ventricle, but by the age of 10 months the adult ratio had been attained. This is in keeping with findings of Recavarren and Arias-Stella (1962), who found that the adult ratio of ventricular weights, as judged from heart slices, was reached by the fourth month of life.

RELATIONSHIP OF ALVEOLAR TO PULMONARY ARTERIAL GROWTH

At birth the alveoli, or the saccules serving the function of alveoli, are few in number. The pul- monary arteries are small and few in number and arterial muscle seems to extend but a short way into the acinus.

In the first few months of life the alveoli multiply rapidly. At the same time the arteries grow in size and multiply in number without there being any notable growth of new muscle tissue. Indeed, if interpreted in the light of its external diameter, the muscle of the arterial wall becomes thinned ; the right ventricle also becomes relatively smaller.

Up to the age of 3 years the alveoli multiply rapidly without growing larger, although becoming a little more complex in shape. Within the acinus the arteries also multiply rapidly, but little new muscle develops within their walls, so that the net effect is for the acinus to contain larger arteries with walls free from muscle. It is therefore during the period of most rapid growth of the alveoli that there is relatively the greatest number of non-muscular arteries within the acinus. By the age of 5 years the alveoli are multiplying more slowly and are growing larger in diameter as well as still more complex in profile. The growth in number of the arteries has slowed, but the arteries continue to grow in size with little new muscle appearing in their walls, so that large non-muscular arteries are still found within the acinus.

Although muscle gradually penetrates into the acinus, even at 11 years it still contains large arteries with little or no muscle in their walls. By the age of 19 years the adult pattern is reached.

We are grateful for the assistance we have received from Professor Keith Simpson, Guy's Hospital, Professor Donald Teare, St. George's Hospital, Dr. Norman France, Queen Elizabeth Hospital for Children, and Dr. H. E. M. Kaye, Royal Marsden Hospital.

Boyden, E. A. (1965). The terminal air sacs and their blood supply in a 37-day infant lung. Amer. J. Anat., 116, 413.

(1967). Notes on the development of the lung in infancy and early childhood. Amer. J. Anat., 121, 749.

Bucher, U., and Reid, L. (1961). Development of the intrasegmental bronchial tree: the pattern of branching and development of cartilage at various stages of intra-uterine life. Thorax, 16, 207.

Dammann, J. F., and Ferencz, C. (1956). The significance of the pulmonary vascular bed in congenital heart disease. I. Normal lungs. II. Malformations of the heart in which there is pulmonary stenosis. Amer. Heart J., 52, 7.

Dunnill, M. S. (1962a). Quantitative methods in the study of pul monary pathology. Thorax, 17, 320 .

- (1962b). Postnatal growth of the lung. Thorax, 17, 329.

Elliott, F. M. (1964). The Pulmonary Artery System in Norma and Diseased Lungs-Structure in relation to Pattern of Branching. Ph.D. Thesis, University of London.

- and Reid, L. (1965). Some new facts about the pulmonary artery and its branching pattern. Clin. Radiol., 16, 193.

Fulton, R. M., Hutchinson, E. C., and Morgan Jones, A. (1952). Ventricular weight in cardiac hypertrophy. Brit. Heart J., 14, 413 . 
Hislop, A. (1969). The non-muscular phase of the pulmonary circulation in the child. In Proceedings of the Fifth International Cystic Fibrosis Conference, Cambridge, September 22-26, 1969, p. 340, ed. D. Lawson. Cystic Fibrosis Research Trust, London.

Keen, E. N. (1955). The postnatal development of the human cardiac ventricles. J. Anat. (Lond)., 89, 484.

Millard, F. J. C. (1965). The Development and the Electrocardiographic Diagnosis of Right Ventricular Hypertrophy in Chronic Lung Disease. M.D. Thesis, University of London.

O'Neal, R. M., Thomas, W. A., and Hartroft, P. M. (1955). The media of small muscular pulmonary arteries in mitral stenosis. Arch. Path., 60, 267.

Recavarren, S., and Arias-Stella, J. (1962). Topography of right ventricular hypertrophy in children native to high altitude. Amer. J. Path., 41, 467.
Reid, L. (1967a). The embryology of the lung. In Ciba Foundation Symposium: Development of the Lung. p. 109. Edited by de Reuck, A. V. S., and Porter, R. Churchill, London.

(1967b). The Pathology of Emphysema. Lloyd-Luke, London.

Rosen, L., Bowden, D. H., and Uchida, I. (1957). Structural chan in pulmonary arteries in first year of life. Arch. Path., 63, 316.

Short, D. S. (1956). Post-mortem pulmonary arteriography with special reference to the study of pulmonary hypertensicn. J. Fac. Radiol. (Lond.), 8, 118.

Wagenvoort, C. A. (1960). Vasoconstriction and medial hypertrophy in pulmonary hypertension. Circulation, 22, 535 .

- Neufeld, H. N., and Edwards, J. E. (1961). The structure of the pulmonary arterial tree in fetal and early postnatal life Lab. Invest., 10, 751 .

Weibel, E. R., and Gomez, D. M. (1962). A principle for counting tissue structures on random sections. J. appl. Physiol., 17, 343.

Willson, H. G. (1928). Postnatal development of the lung. Amer. J. Anat., 41, 97. 